\title{
In Vivo Measurement of the Friction Between Human Skin and Different Medical Compression Stockings
}

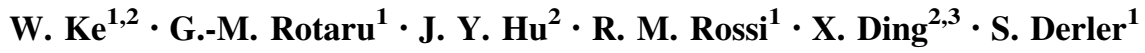

Received: 17 June 2015/ Accepted: 21 August 2015

(C) Springer Science+Business Media New York 2015

\begin{abstract}
The friction behaviour of five medical compression stockings (MCSs) against forearm skin was investigated in vivo as a function of normal load under dry and wet conditions. In addition, the interfacial moisture transport and skin hydration were analysed to understand the influence on friction. The friction coefficients of dry fabrics showed no significant differences between a traditional MCS and versions with modified material composition and base structure. Under wet conditions, the modified MCS fabrics showed considerably lower friction coefficients than the traditional MCS fabric. Changes in the material composition led to 20-30\% lower friction coefficients, different base structures to 50-60\% lower friction. The water transport properties of the MCS fabrics suggest that removal of interfacial water is useful for reducing the friction between MCSs and skin. The results provide information for the optimisation of MCSs regarding improved comfort and moisture transport properties.
\end{abstract}

Keywords Bio-tribology $\cdot$ Skin friction $\cdot$ Medical compression stockings · Interfacial water - Skin hydration

S. Derler

Siegfried.Derler@empa.ch

1 Empa, Swiss Federal Laboratories for Materials Science and Technology, Laboratory for Protection and Physiology, Lerchenfeldstrasse 5, 9014 St. Gallen, Switzerland

2 College of Textiles, Donghua University, Shanghai 201620, People's Republic of China

3 Key Laboratory of Textile Science and Technology, Ministry of Education of China (Donghua University), Shanghai 201620, People's Republic of China

\section{Introduction}

Although medical compression stockings (MCSs) have long been proven to be an efficient compression therapy for venous diseases [1-3], patients are not always willing to use them even if suffering from pain. According to an international questionnaire survey on the use of MCSs [4], the main reasons for abstaining to wear the stockings are difficulties in putting them on and discomfort feelings during long-time use. Both the difficulty to put on a MCS and discomfort are closely linked to the friction of the stocking against human skin. The higher the friction between MCS and skin, the more difficult it is to wear the stocking [5]. In addition, perspiration during the use can cause a moist or wet interface between skin and MCS, which increases the friction coefficient and leads to discomfort feelings [6-8]. Thus, it is assumed that reducing the friction at the skin-MCS interface could improve the usability and sensorial comfort of MCSs, which is an urgent issue for manufacturers.

The surface properties of the fabrics and water or moisture at the skin-textile interface have been reported to be two important factors in determining the friction between textiles and skin [9-11]. The textile construction and the fibre materials and properties determine the surface texture and properties of textiles and therefore influence the friction behaviour. Water or moisture commonly increases the friction at the skin-textile interface by a factor of 1.5-7 compared to dry friction [12]. Li et al. [13] found that wool and nylon prosthetic socks had higher friction coefficients due to their coarse knitting weave surfaces and hard protruding textile fibres, while lower friction coefficients and less discomfort sensations were observed for cotton and silk socks due to their soft and smooth surface features. Baussan et al. [14] discussed the influence of fabric structures on the prevention of blisters by measuring the 
friction of various running socks and concluded that terry jersey socks generate relatively low friction due to their compact and homogeneous surface. Bertaux et al. [15] found low friction coefficients and comfortable sensations for socks consisting of synthetic fibres, which in comparison with cotton socks keep the feet dry by transporting the perspiration out of the socks. Bogerd et al. [16] reported that a wool/polyamide blend sock showed less friction and was more comfortable than a polypropylene sock, because of a larger moisture absorption capacity. While the surface properties of textiles are generally important for the friction behaviour, the water absorption and transportation capacity of fabric materials seem particularly relevant under moist and wet conditions. Thus, manufacturers need to take into account the material composition as well as textile structures in the optimisation of socks.

Medical compression stockings are known to be different from normal socks [17]. They include two components which are normally made of different materials: a layer of inlaid yarns and a layer of knitted loops. The friction behaviour and the water absorption and transportation capacity are expected to vary with the textile construction as well as the fibre composition.

The objective of the present study was to investigate the friction behaviour of different MCSs under both dry and wet conditions, in order to assess the role of the material composition and base structure. In vivo skin friction measurements were taken under varying normal loads. To analyse the friction between human skin and MCSs in detail, skin hydration measurements and micro-computer tomography experiments concerning the water distribution and transport within MCS fabrics were performed additionally. The obtained results can contribute to the design of better acceptable and more comfortable medical textiles.

\section{Experimental}

\subsection{Investigated Medical Compression Stockings}

Five types of commercially available MCSs from one manufacturer were investigated. All stockings were characterised by pressure class 2 (moderate compression intensity), corresponding to the most prescribed products in Europe. The selected samples represented a range of products including a typical, traditional MCS as well as modified versions designed for improved comfort and moisture management by varying the material composition or the fabric base structure (Table 1). Figure 1 shows a typical structure of a MCS (left) as well as the base structure of MCSs with original plain jersey or variable jersey (right).

The MCS samples were cut from the ankle area and investigated in the unstretched state, although they are stretched during practical use. In a previous study, the friction of MCS fabrics was found to be independent of the strain state [18]. Figure 2 shows microscopic images of the MCS samples (the inner surface which is next to the skin). The surface of sample S1 appears rougher and less regular than the surfaces of the other samples.

\subsection{In Vivo Friction Measurements}

The friction between MCS samples and human skin was investigated in four subjects (two males and two females, aged between 25 and 31 years) without a history of skin disease. The skin of the volar forearm was chosen for convenience because its properties were found to correlate well with those of skin at the legs [19]. The subjects rubbed their volar forearm against MCS samples attached on a quartz 3-component dynamometer (Kistler, type 9254, Winterthur, Switzerland) with dimensions of $15 \times 10 \mathrm{~cm}$. The method was described previously [20, 21]. The movement of the forearm was towards the body, parallel to the longitudinal axis of the force plate and perpendicular to the inlaid yarn direction of the MCS samples. The sliding direction corresponded to the length axis of the leg along which a MCS is tightened.

To simulate the natural and sweating or perspiration state, friction measurements were taken under dry and wet conditions. The wet state was obtained by evenly distributing deionised water over the textile sample using a syringe. Deionised water was found to be appropriate to simulate sweating in previous friction experiments [22].

For each sample and condition (dry and wet), each subject carried out 150 single friction measurements at different normal loads between slightly above 0 and $10 \mathrm{~N}$. For convenience, these friction measurements were divided into 15 measurement periods of $20 \mathrm{~s}$, during which the subjects performed ten individual sliding friction movements. The sliding distances were between 50 and $100 \mathrm{~mm}$ and the sliding velocities between 50 and $150 \mathrm{~mm} / \mathrm{s}$. The subjects applied a constant normal force on the forearm during individual sliding movements and randomly changed the applied force from one sliding movement to the next. Results for normal forces smaller than $0.15 \mathrm{~N}$ were excluded from the data analyses because of their high measurement uncertainty. As an example, Fig. 3 shows measurement results for a single sliding friction contact at a normal load of about $6 \mathrm{~N}$. Friction coefficients were determined from the middle part of the measured force signals (friction force divided by normal force).

All friction experiments were conducted in a conditioned room at a temperature of $(23 \pm 1){ }^{\circ} \mathrm{C}$ and a relative humidity of $(50 \pm 5) \%$. The subjects acclimatised to the ambient conditions for at least $10 \mathrm{~min}$, and the skin was 
Table 1 Basic characteristics of the investigated MCS fabrics and specification of the constituent yarns

\begin{tabular}{|c|c|c|c|c|c|c|c|}
\hline Sample & Description & $\begin{array}{l}\text { Base } \\
\text { structure }\end{array}$ & $\begin{array}{l}\text { Fibre } \\
\text { composition }\end{array}$ & Loop yarn materials & Inlaid yarn materials & $\begin{array}{l}\text { Thickness } \\
(\mathrm{mm})\end{array}$ & $\begin{array}{l}\text { Water } \\
\text { contact angle } \\
\left({ }^{\circ}\right)\end{array}$ \\
\hline $\mathrm{S} 1$ & $\begin{array}{l}\text { Traditional MCS } \\
\text { fabric }\end{array}$ & $\begin{array}{l}\text { Jersey } \\
2 * 1\end{array}$ & $\begin{array}{l}70 \% \text { PA } \\
30 \% \text { elastane }\end{array}$ & $\begin{array}{l}\text { Core yarn: 90er } \\
\text { Heveafil } \\
\text { First covering yarn: } 23 \\
\text { dtex ( } 78 \mathrm{f} \text { ) PA } \\
\text { Second covering yarn: } \\
23 \text { dtex ( } 78 \mathrm{f} \text { ) PA }\end{array}$ & $\begin{array}{l}\text { Core yarn: } 65 \text { er natural } \\
\text { rubber } \\
\text { First covering yarn: } 34 \\
\text { dtex ( } 110 \text { f) PA } \\
\text { Second covering yarn: } \\
34 \text { dtex (110 f) PA }\end{array}$ & $1.18 \pm 0.11$ & $124.1 \pm 0.9$ \\
\hline $\mathrm{S} 2$ & $\begin{array}{l}\text { Variation of } \\
\text { material } \\
\text { composition }\end{array}$ & $\begin{array}{c}\text { Jersey } \\
2 * 1\end{array}$ & $\begin{array}{l}52 \% \text { PA } \\
34 \% \text { elastane } \\
14 \% \text { cotton }\end{array}$ & $\begin{array}{l}\text { Core yarn: 44er Lycra } \\
\text { (mono) } \\
\text { First covering yarn: } 10 \\
\text { dtex ( } 33 \mathrm{f} \text { ) PA } \\
\text { Second covering yarn: } \\
10 \text { dtex ( } 33 \mathrm{f} \text { ) PA }\end{array}$ & $\begin{array}{l}\text { Core yarn: } 475 \text { er Lycra } \\
\text { (mono) } \\
\text { First covering yarn: } 7 \\
\text { dtex ( } 22 \text { f) PA } \\
\text { Second covering yarn: } \\
44 \text { dtex cotton }\end{array}$ & $0.94 \pm 0.01$ & $40.9 \pm 0.6$ \\
\hline S3 & $\begin{array}{l}\text { Variation of } \\
\text { material } \\
\text { composition }\end{array}$ & $\begin{array}{c}\text { Jersey } \\
2 * 1\end{array}$ & $\begin{array}{l}52 \% \text { PA } \\
34 \% \text { elastane } \\
14 \% \text { tencel } \\
\text { (man-made } \\
\text { fibre) }\end{array}$ & $\begin{array}{l}\text { Core yarn: 44er Lycra } \\
\text { (mono) } \\
\text { First covering yarn: } 10 \\
\text { dtex ( } 33 \mathrm{f} \text { ) PA } \\
\text { Second covering yarn: } \\
34 \text { dtex ( } 33 \mathrm{f} \text { ) PA }\end{array}$ & $\begin{array}{l}\text { Core yarn: } 475 \text { er Lycra } \\
\text { (mono) } \\
\text { First covering yarn: } 7 \\
\text { dtex ( } 22 \mathrm{f}) \mathrm{PA} \\
\text { Second covering yarn: } \\
59 \text { dtex tencel }\end{array}$ & $0.95 \pm 0.01$ & $41.1 \pm 1.6$ \\
\hline S4 & $\begin{array}{l}\text { Variation of base } \\
\text { structure }\end{array}$ & $\begin{array}{c}\text { Jersey } \\
1 * 1\end{array}$ & $\begin{array}{l}65 \% \text { PA } \\
35 \% \text { elastane }\end{array}$ & $\begin{array}{l}\text { Core yarn: 78er Lycra } \\
\text { (mono) } \\
\text { First covering yarn: } 20 \\
\text { dtex ( } 33 \mathrm{f} \text { ) PA } \\
\text { Second covering yarn: } \\
20 \text { dtex ( } 33 \mathrm{f} \text { ) PA }\end{array}$ & $\begin{array}{l}\text { Core yarn: } 475 \text { er Lycra } \\
\text { (mono) } \\
\text { First covering yarn: } 34 \\
\text { dtex (44 f) PA }\end{array}$ & $0.85 \pm 0.01$ & $46.5 \pm 0.7$ \\
\hline S5 & $\begin{array}{l}\text { Variation of base } \\
\text { structure }\end{array}$ & $\begin{array}{c}\text { Jersey } \\
1 * 1\end{array}$ & $\begin{array}{l}61 \% \text { PA } \\
39 \% \text { elastane }\end{array}$ & $\begin{array}{l}\text { Core yarn: 44er Roica } \\
\text { First covering yarn: } 34 \\
\text { dtex ( } 44 \text { f) PA } \\
\text { Second covering yarn: } \\
14 \text { dtex ( } 22 \mathrm{f} \text { ) PA }\end{array}$ & $\begin{array}{l}\text { Core yarn: } 475 \text { er Lycra } \\
\text { (mono) } \\
\text { First covering yarn: } 7 \\
\text { dtex }(22 \mathrm{f}) \mathrm{PA}\end{array}$ & $0.78 \pm 0.01$ & $39.9 \pm 1.8$ \\
\hline
\end{tabular}

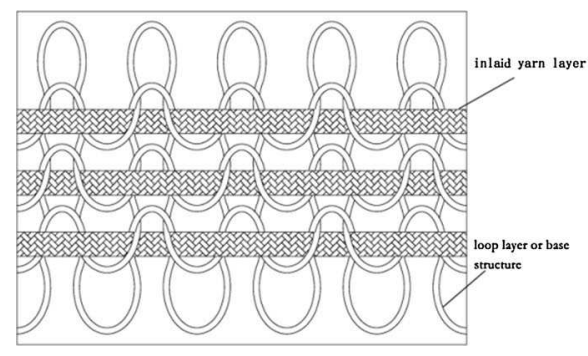

Fig. 1 Left a typical structure of a medical compression stocking. The inlaid yarn layer is inserted within the loop layer. Right schematic cross section of the MCS fabric. $a$ Structure of MCS samples S1-S3

cleaned with ethanol prior to the measurements. Fresh MCS samples were used for each subject and condition.

\subsection{Skin Hydration Measurements}

Skin hydration was assessed at approximately 15 positions within the contact zone of the forearm by using a (a)

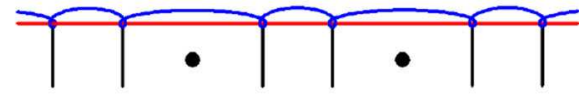

(b)

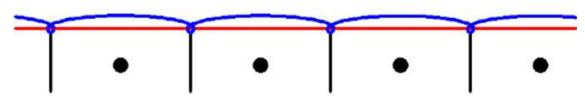

and $b$ structure of MCS samples S4 and S5. The blue curve represents the loop yarn and the red line the inlaid yarn (Color figure online)

Corneometer $825 \mathrm{CM}$ (Courage \& Khazaka, Cologne, Germany). The measurements provided information on the epidermal moisture content up to a depth of 10-20 $\mu \mathrm{m}$ (around the thickness of the stratum corneum). Skin hydration was investigated before and after the friction measurements. Measurement results are given in arbitrary units, named $\mathrm{CM}$ value. The range of $\mathrm{CM}$ values is from 0 

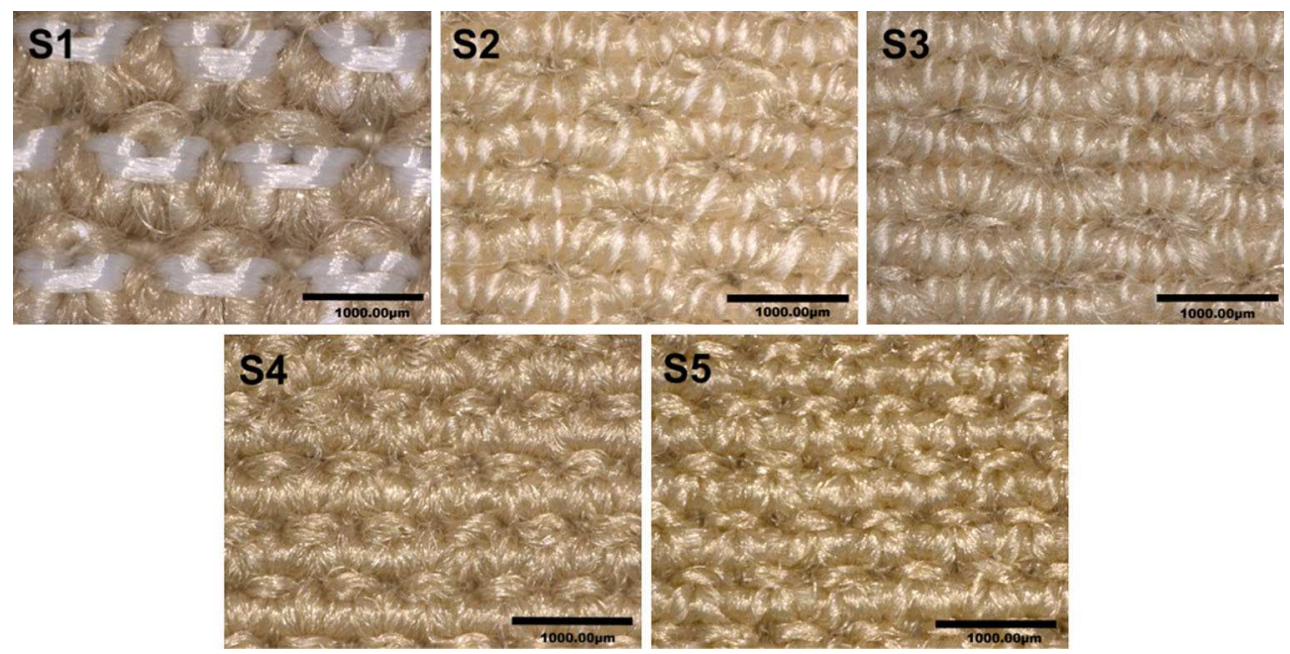

Fig. 2 Microscopic images of the MCS samples (magnification 100). The horizontal direction is the direction of the inlaid yarn, running along the circumference of the leg

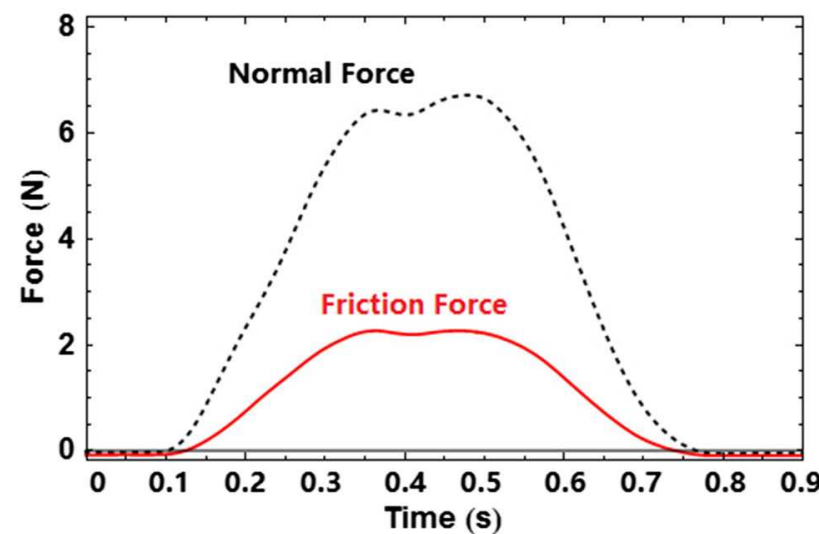

Fig. 3 Example of force signals measured in a single sliding friction contact under dry conditions

to 120 , whereby values greater than 40 characterise normally moist skin, values between 30 and 40 dry skin and values below 30 very dry skin [23].

\subsection{Measurement of Moisture Distribution and Transport Within MCS Samples}

The moisture distribution and transport within the MCS samples were measured by means of a micro-computer X-ray tomograph ( $\mu$-CT80 of Scanco Medical AG, Brüttisellen, Switzerland), allowing to characterise textiles under simulated physiological conditions during physical activity [24].

A single $\mu$-CT experiment included three phases: (1) acclimatisation during 16 min (conditioning within the sample holder and measurement in the dry state); (2) simulated sweating during 64 min (addition of water); (3) recovery for $32 \mathrm{~min}$ (passive drying). These phases correspond roughly to pre-activity, perspiration-inducing activity and post-activity for a person wearing a MCS. Sweating was simulated by providing deionised water from a nozzle located underneath the centre of a MCS sample at a rate of $20 \mu \mathrm{l} / \mathrm{min}$.

$\mathrm{X}$-ray detection took place during the whole period of measurement, thereby averaging the data over intervals of $8 \mathrm{~min}$ (acquisition time of $191 \mathrm{~ms}$ per projection). The spatial resolution of the $\mu$-CT measurements corresponded to cubes with an edge length of $74 \mu \mathrm{m}$. The data processing and visualisation were done by MATLAB using the measurements in the dry state for comparisons. An example of measurement results illustrating vertical water transport within a MCS fabric is shown in Fig. 4.

All the measurements were processed in an air-conditioned laboratory with a temperature of $(23 \pm 1){ }^{\circ} \mathrm{C}$ and a relative humidity of $(50 \pm 5) \%$. Before the samples were attached to the sample holder, they were pre-conditioned for at least $72 \mathrm{~h}$.

\section{Results}

\subsection{Range of Friction Coefficients of MCS Fabrics Against Human Skin}

Table 2 shows the mean values and ranges of friction coefficients between the MCS samples and forearm skin of all subjects at the normal loads from 0.15 to $10 \mathrm{~N}$ under dry and wet conditions. Generally, the mean friction coefficients of all MCS samples observed under wet condition were higher than those under dry condition, with a factor from 1.21 to 2.69 , which was in accordance with 
Fig. 4 Example of the X-ray measurement results for sample S4. a Vertical water distribution as a function of time. The dashed line indicates the middle of the MCS fabric (half thickness) which is used to separate the inner part next to the skin from the outside part of the MCS sample.

b Development of the water content as a function of time within the whole fabric sample and for the inner and outer part
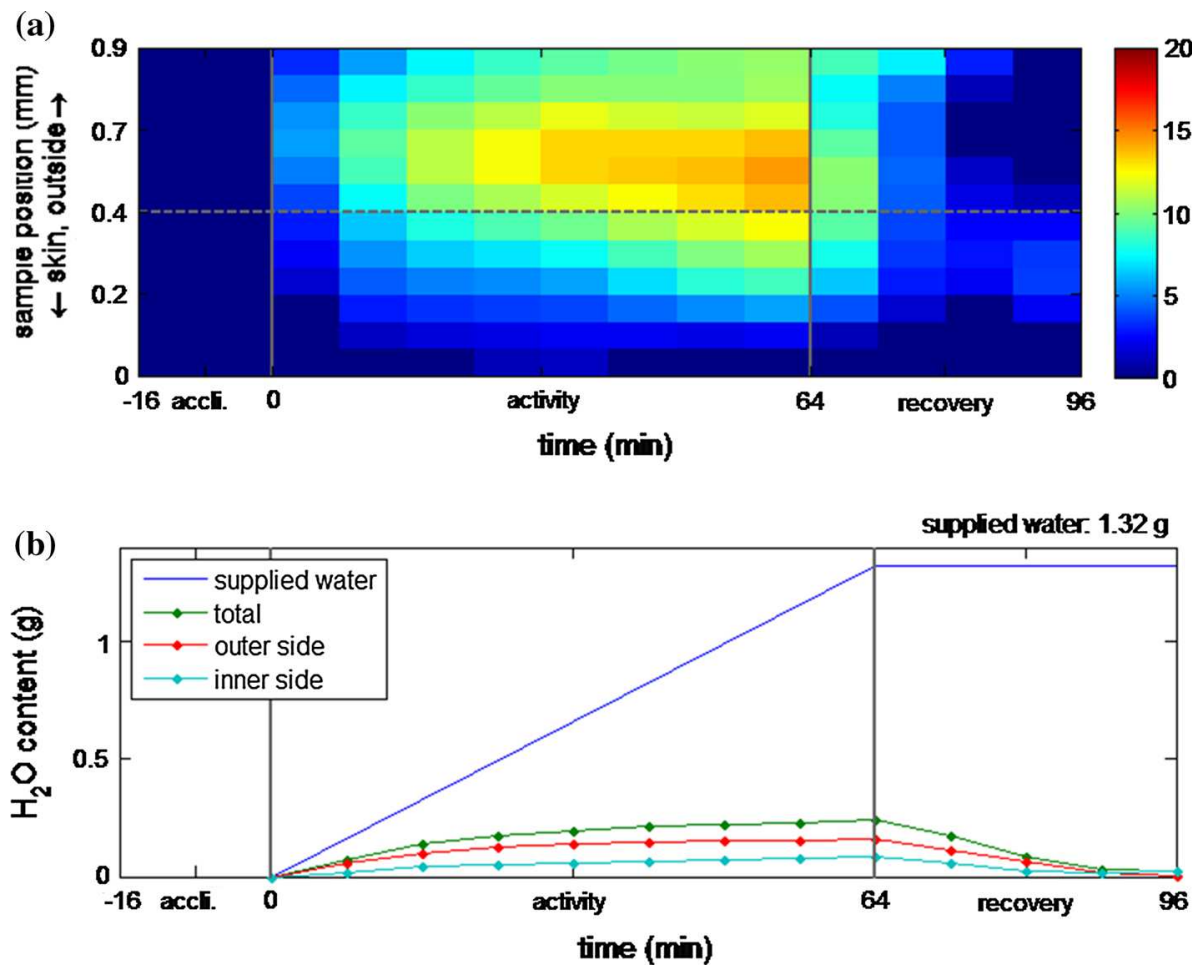

Table 2 Mean values and standard deviations of friction coefficients of MCS samples at normal loads up to $10 \mathrm{~N}$ under both dry and wet conditions

\begin{tabular}{llllll}
\hline Sample & \multicolumn{2}{l}{ Coefficient of friction } \\
\cline { 2 - 3 } & \multicolumn{2}{l}{ Dry condition } & & & \multicolumn{2}{l}{ Wet condition } \\
\cline { 2 - 3 } \cline { 5 - 6 } & Mean \pm SD & Range & & Mean \pm SD & Range \\
\hline S1 & $0.39 \pm 0.05$ & $0.24-0.54$ & & $1.05 \pm 0.22$ & $0.52-1.75$ \\
S2 & $0.36 \pm 0.04$ & $0.15-0.67$ & & $0.73 \pm 0.10$ & $0.43-1.07$ \\
S3 & $0.34 \pm 0.03$ & $0.15-0.65$ & & $0.85 \pm 0.18$ & $0.36-1.41$ \\
S4 & $0.38 \pm 0.04$ & $0.24-0.48$ & & $0.44 \pm 0.07$ & $0.31-0.60$ \\
S5 & $0.34 \pm 0.02$ & $0.23-0.41$ & & $0.41 \pm 0.07$ & $0.22-0.62$ \\
\hline
\end{tabular}

literature data on skin-textile friction [12]. In the dry condition, the mean friction coefficients of all MCS samples were around 0.36 , showing no significant differences between the MCS samples. Under wet conditions, the modified MCS samples S2, S3, S4 and S5 showed lower friction coefficients than the traditional MCS sample S1. The friction coefficients of MCS S2 and S3 were decreased by around 20 and $30 \%$, respectively, and 58 and $60 \%$ for S4 and S5 under wet conditions. It also can be seen that the friction coefficients varied over wide ranges for all MCS fabrics, especially under wet conditions. Compared to sample S1, a relatively narrow range was observed for samples S4 and S5 under both dry and wet conditions.

\subsection{Load Dependence and Friction Mechanism of MCS Fabrics}

For all subjects, the measured friction coefficients showed decreasing trends with increasing normal loads under both dry and wet conditions. As an example, Fig. 5 summarises the friction coefficients against MCS samples as a function of normal loads for one subject. Under dry conditions, the coefficients of friction of all MCS samples varied within a narrow range around the mean value. In linear data fits, the slopes $\left(b_{1}\right.$ in Fig. 5) were close to zero, indicating no dependence on the normal load.

In the wet condition, however, the friction coefficients of all MCS samples were characterised by distinct decreases under normal loads below $2 \mathrm{~N}$, followed by rather constant values at higher forces. Further examination shows that the decrease in the friction coefficients at low normal loads is rather moderate for samples S4 and S5, while the other three samples exhibit a sharp decrease. The most pronounced load dependence was observed for the traditional MCS sample (S1). The systematic decrease in friction coefficients with increasing loads under wet conditions was analysed by fitting the data with functions of the form $\mu(N)=a+b N^{-1 / 3}$ (Fig. 5). 
Fig. 5 Load dependence of friction coefficients between the skin and the MCS samples for one subject. The data measured in dry and wet condition were fitted by the linear function $\mu(N)=a_{1}+b_{1} N$ and the power function $\mu(N)=a_{2}+b_{2} N^{-1 / 3}$, respectively
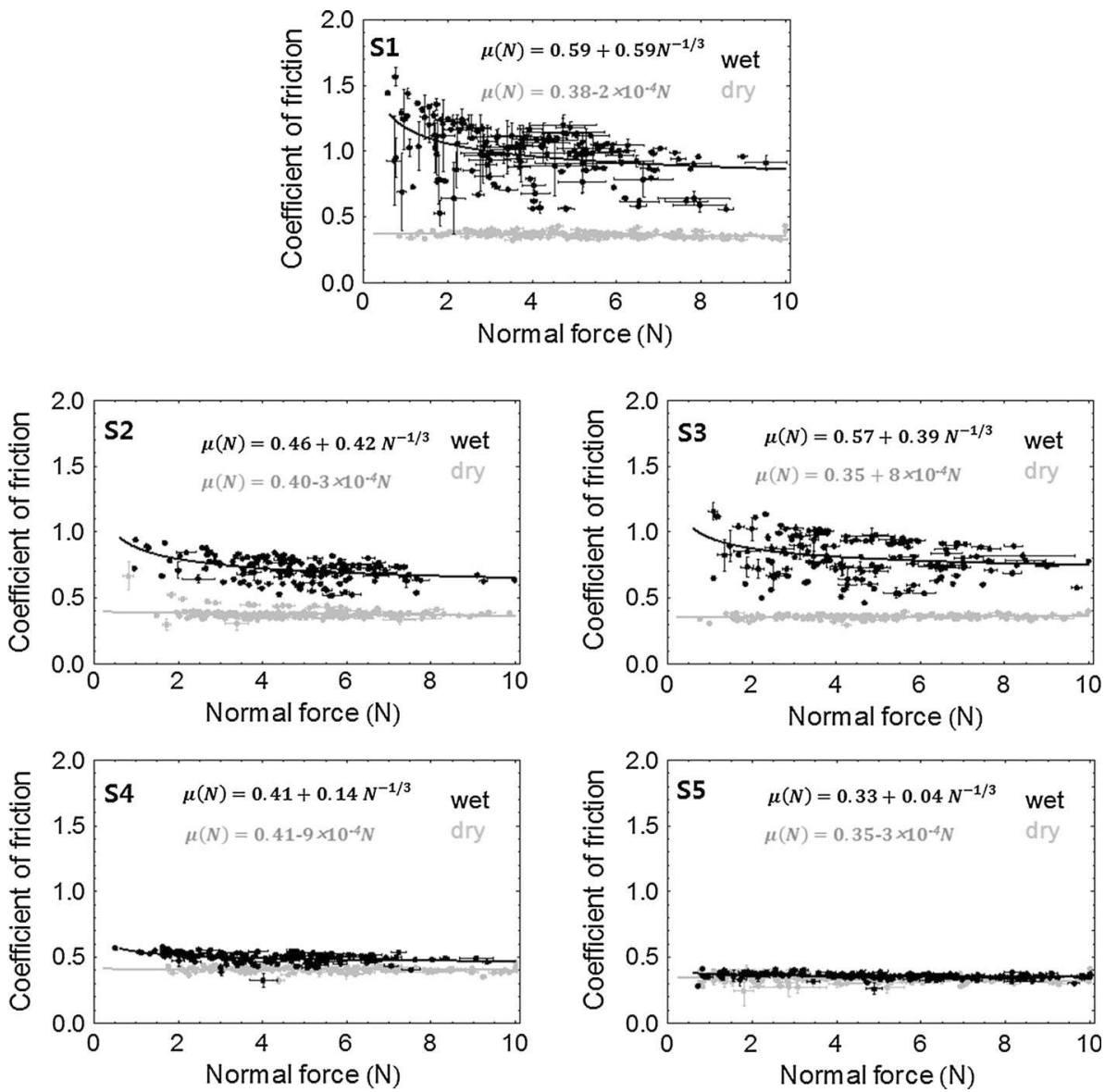

\subsection{Skin Hydration Measurements}

Table 3 summarises the results of skin hydration measurements for all subjects after friction measurements on dry and wet MCS samples, respectively. Moisture uptake of the skin when sliding on wet fabrics led to systematically enhanced skin hydration levels.

\subsection{Moisture Distribution and Transport Measurements}

Figure 6 shows the water content observed along the fabric thicknesses for the data acquired at the beginning of the sweating phase, corresponding to the time of a single friction measurement. The maximum water content (in \% of the supplied water) in sample S1 was observed near the skin surface, within the first layer with a thickness of $0.074 \mathrm{~mm}$ (given by the spatial resolution of the $\mu-\mathrm{CT}$ measurements). In contrast, the modified versions of MCS samples exhibited a maximum in the seventh to ninth layer, i.e. several layers away from the skin-fabric interface and towards the outer part of the samples. The results for all the modified MCS samples were comparable and indicated a more efficient vertical water transport than sample S1.
The comparison of the average water content measured near the skin-fabric interface (the first three layers with a total thickness of $0.222 \mathrm{~mm}$ near the skin model) as a function of time is shown in Fig. 7. It can be seen that sample S1 contained the highest percentage of water, stabilising at a value of about $27 \%$, followed by sample S3 with a water content up to around $20 \%$. The samples S2, S4 and S5 exhibited the lowest water contents within the layers next to the skin (between 5 and $10 \%$ ).

\section{Discussion}

Friction coefficients of dry and wet MCS samples were measured against the forearm skin of four subjects as a function of the normal load. The friction coefficients of dry MCSs showed comparable values around 0.35 and were practically independent of the normal load. This can be attributed to the specific structure of MCS fabrics. The inlaid yarn of MCSs plays a key role in forming the topography, resulting in similar geometrical features and real contact areas against human skin [18, 25].

Under wet conditions, the friction coefficients of all the MCS samples exhibited a load dependence, indicating that 

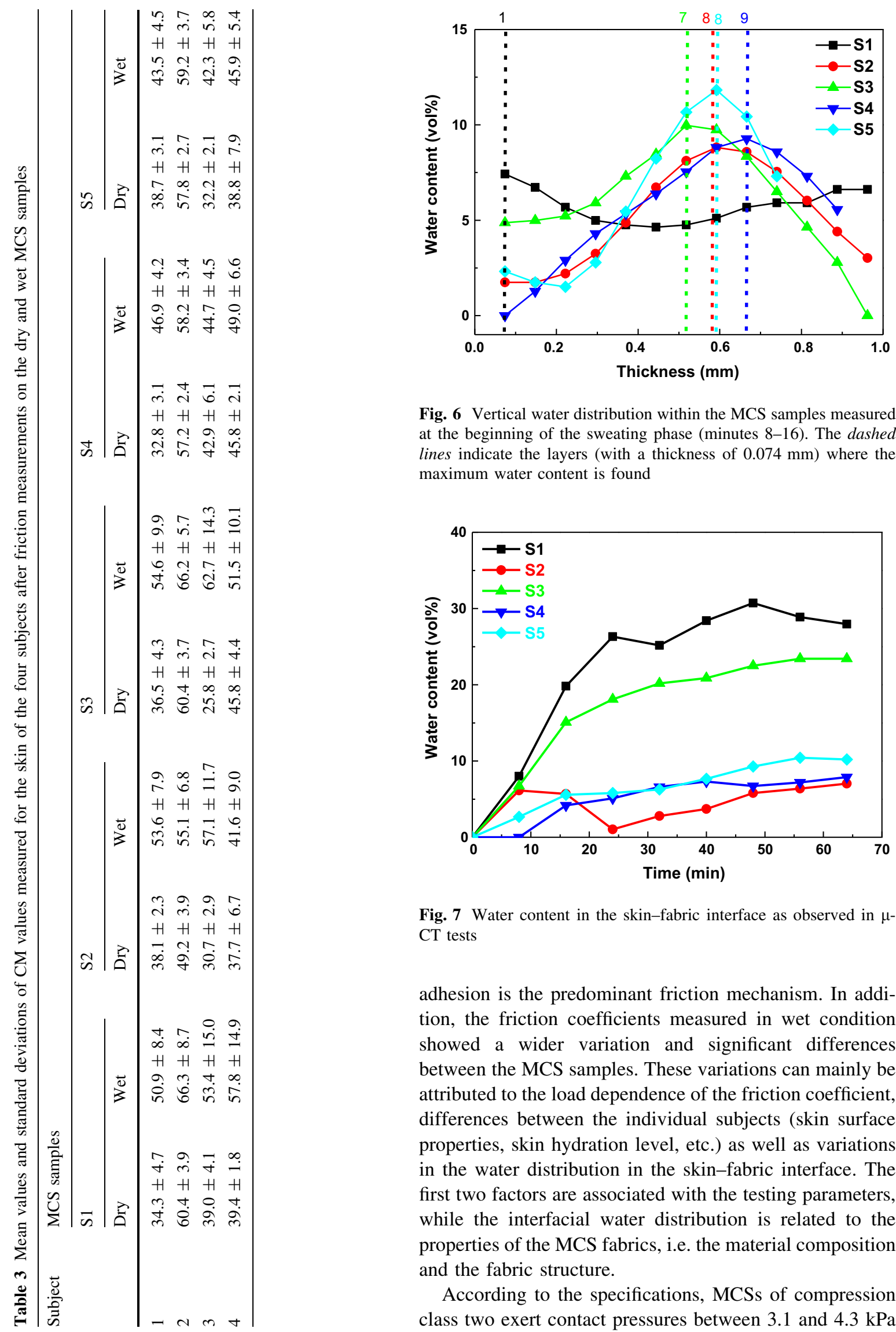

Fig. 6 Vertical water distribution within the MCS samples measured at the beginning of the sweating phase (minutes 8-16). The dashed lines indicate the layers (with a thickness of $0.074 \mathrm{~mm}$ ) where the maximum water content is found

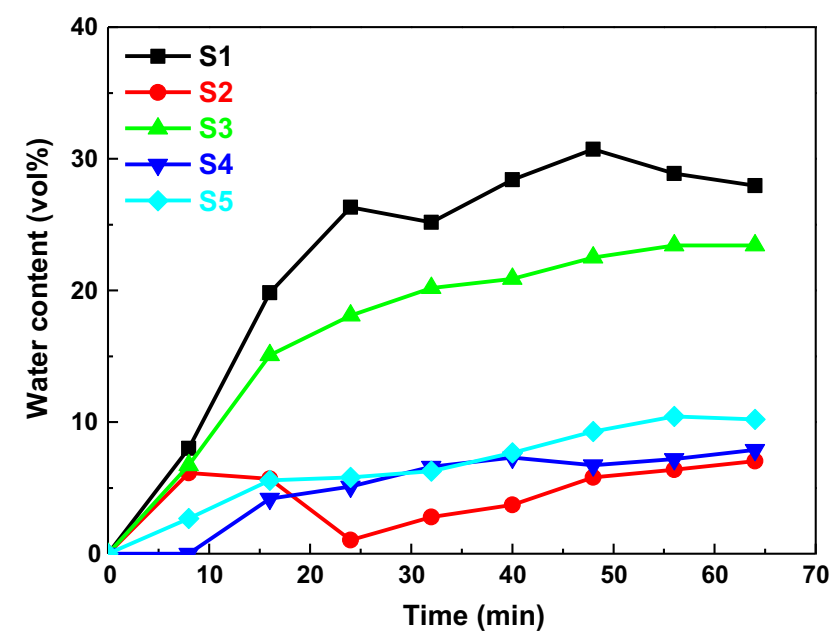

Fig. 7 Water content in the skin-fabric interface as observed in $\mu$ CT tests

adhesion is the predominant friction mechanism. In addition, the friction coefficients measured in wet condition showed a wider variation and significant differences between the MCS samples. These variations can mainly be attributed to the load dependence of the friction coefficient, differences between the individual subjects (skin surface properties, skin hydration level, etc.) as well as variations in the water distribution in the skin-fabric interface. The first two factors are associated with the testing parameters, while the interfacial water distribution is related to the properties of the MCS fabrics, i.e. the material composition and the fabric structure.

According to the specifications, MCSs of compression class two exert contact pressures between 3.1 and $4.3 \mathrm{kPa}$ 
on the ankle part of the leg [26]. In a previous study, it was reported that the mean pressure on the volar forearm was around $2 \mathrm{kPa}$ when loaded by normal forces of $10 \mathrm{~N}$ [21]. Because the friction coefficients between skin and MCS samples were found to be almost constant for normal forces between 4 and $10 \mathrm{~N}$, it is assumed that the friction measurement results in this range are also representative for higher loads and, thus, relevant for contact conditions occurring in practice when wearing MCSs.

Figure 8 illustrates the friction coefficients of the MCS samples, measured for normal forces between 4 and $10 \mathrm{~N}$. There were no significant differences between the samples under dry conditions. In the case of the traditional MCS sample (S1), the application of water led to a significant increase in the friction coefficients, which ranged from 0.52 to 1.31 . For samples $\mathrm{S} 2$ and $\mathrm{S} 3$, the friction coefficients under wet conditions were $0.43-0.90$ and $0.39-1.08$, respectively. Samples S4 and S5 showed the lowest friction coefficients under wet conditions, ranging from 0.26 to 0.58 . Thus, the application of water only slightly increased friction compared to the dry condition. In general, interfacial water tended to increase the measured friction coefficients. The influence of water on friction was pronounced for the samples S1, S2 and S3, especially for the traditional MCS sample (S1), but rather small for the samples S4 and S5.

Gerhardt et al. [9] have found that the skin friction coefficient increases linearly with increasing skin hydration. Per unit increase in skin hydration, the friction coefficient would increase with $0.01-0.02$. When investigating the influence of skin hydration on various bed sheets, Rotaru et al. [21] concluded that the influence of skin hydration cannot be ignored when analysing in vivo friction measurement data. In the present case, the increase in

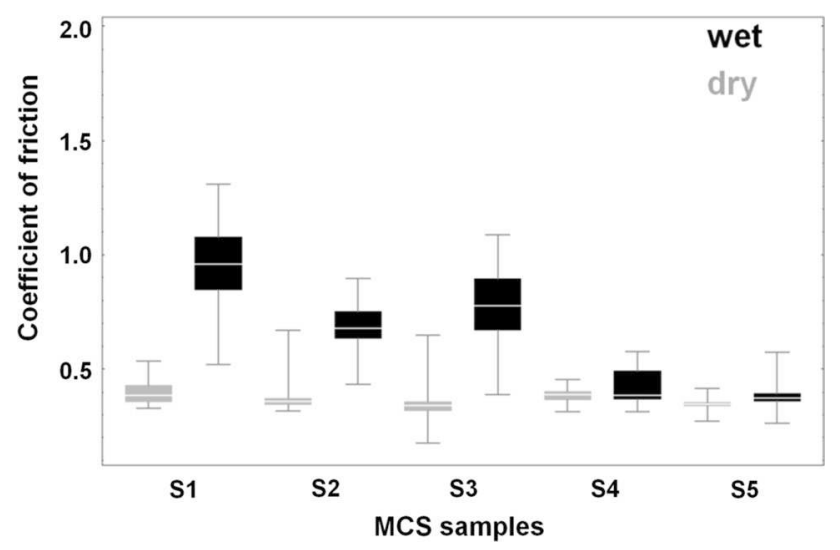

Fig. 8 Friction coefficients between forearm skin and MCS fabrics (four subjects) measured at normal forces between 4 and $10 \mathrm{~N}$. The boxes indicate the range between the lower and upper quartile, the white lines within the boxes the median, and the whiskers the range of the measurement data the friction coefficient was about 0.55 for sample $\mathrm{S} 1$, while for samples S4 and S5, there were no significant differences between dry and wet conditions on the basis of an ANOVA. This implies that the variation of friction coefficients under wet conditions can be primarily attributed to the change of the amount of interfacial water by water absorption of the MCS samples with varying material composition and fabric construction.

The $\mu$-CT measurements also indicated that the variation in the moisture content of the MCS samples is an important factor for the differences in the friction of MCSs under wet conditions. The traditional MCS sample (S1) based on a synthetic inlaid yarn performed poorly with regard to transporting water away from the skin. It showed the greatest water uptake near the fabric surface as well as the highest friction coefficients. Samples S2 and S3 with inlaid yarns consisting of cotton and tencel fibres showed comparable water transport and absorption. Cotton and tencel are known for their similar moisture management. Their friction coefficients were decreased by $20-30 \%$ compared to sample S1. Water had barely an influence on the friction of samples S4 and S5, showing around $60 \%$ lower friction coefficients than sample S1. Due to their bigger air gaps within the plain jersey structure compared to the traditional MCS, the water was transported fast and efficiently, leading to a relatively dry MCS-skin interface and, as a consequence, to low friction coefficients under wet conditions. It can be concluded that both fibre materials and base structure have an influence on the wet friction behaviour of MCSs by absorbing and transporting water which is present in the MCS-skin interface. The base structure is especially important by influencing the surface roughness and by affecting the material repartition in the thickness direction.

\section{Conclusions}

The tribological behaviour of five medical compression stockings with different material composition and base structure were investigated in vivo under both dry and wet conditions. The friction coefficients of a traditional MCS and modified versions were comparable under dry conditions, mainly because of the special structure of MCS fabrics leading to similar contact geometries. Interfacial water increased the friction coefficients of the MCS samples by factors between 1.1 and 2.9. By changing either the material composition or the base structure of the MCS fabric, the friction coefficient under wet conditions was reduced by around 30 and $60 \%$, respectively, compared to a traditional MCS. These results contribute to a better understanding of the friction between the human skin and medical compression stockings and support the further optimisation of MCSs by manufacturers. 
Acknowledgments We thank the volunteers for participating in the in vivo friction experiments and Ivo Rechsteiner for his assistance with the $\mu$-CT measurements. We also thank Sigvaris AG, St. Gallen, for providing samples of medical compression stockings. The first author acknowledges the support of CSC Scholarship from the Ministry of Education of P.R. China. Part of this work was supported by the National Natural Science Foundation (Project No. 51175076).

\section{References}

1. Benigni, J.-P., Deman, A.-L., Uhl, J.-F.: Compression stockings for treating venous leg ulcers. Ulcers 2013, Article ID 686491 (2013)

2. Dennis, M., Sandercock, P.A.G., Reid, J., Graham, C., Murray, G., Venables, G., Rudd, A., Bowler, G.: Effectiveness of thighlength graduated compression stockings to reduce the risk of deep vein thrombosis after stroke (CLOTS trial 1): a multicentre, randomised controlled trial. Lancet 373, 1958-1965 (2009)

3. Liu, R.: Comfort and mechanical function of compression stockings. PhD Thesis, The Hong Kong Polytechnic University, Institute of Textiles and Clothing (2006)

4. Partsch, B., Pannier, F., Partsch, H., Rabe, E.: Use of compression stockings after deep vein thrombosis in an international surveyresults from a questionnaire. Vasomed 17(3), 82-87 (2005)

5. LeFloch, E., Rastel, D.: How to improve compliance of compression therapy (20-36 mm Hg). Robert Stemmer Library on Compression Therapy. Compression Bull. 17, 16 (2001)

6. Bogerd, C.P., Rechsteiner, I., Wüst, B., Rossi, R.M., Brühwiler, P.A.: The effect of two sock fabrics on physiological parameters associated with blister incidence: a laboratory study. Ann. Occup. Hyg. 55(5), 510-518 (2011)

7. Strese, H., Kuck, M., Benken, R., Fluhr, J.W., Schanzer, S., Richter, H., Meinke, M.C., Beuthan, J., Benderoth, C., Frankowski, G., Sterry, W., Lademann, J.: Influence of finishing textile materials on the reduction of skin irritations. Skin Res. Technol. 19(1), e409-e416 (2013)

8. Zhong, W., Xing, M.M.Q., Pan, N., Maibach, H.I.: Textiles and human skin, microclimate, cutaneous reactions: an overview. Cutan. Ocul. Toxicol. 25(1), 23-39 (2006)

9. Gerhardt, L.-C., Strässle, V., Lenz, A., Spencer, N.D., Derler, S.: Influence of epidermal hydration on the friction of human skin against textiles. J. R. Soc. Interface 5, 1317-1328 (2008)

10. Kim, M.-S., Kim, I.-Y., Park, Y.-K., Lee, Y.-Z.: The friction measurement between finger skin and material surfaces. Wear 301(1-2), 338-342 (2013)

11. Ramalho, A., Szekeres, P., Fernandes, E.: Friction and tactile perception of textile fabrics. Tribol. Int. 63, 29-33 (2013)

12. Derler, S., Gerhardt, L.-C.: Tribology of skin: review and analysis of experimental results for the friction coefficient of human skin. Tribol. Lett. 45(1), 1-27 (2012)
13. Li, W., Liu, X.D., Cai, Z.B., Zheng, J., Zhou, Z.R.: Effect of prosthetic socks on the frictional properties of residual limb skin. Wear 271(11-12), 2804-2811 (2011)

14. Baussan, E., Bueno, M.A., Rossi, R.M., Derler, S.: Analysis of current running sock structures with regard to blister prevention. Text. Res. J. 83(8), 836-848 (2013)

15. Bertaux, E., Derler, S., Rossi, R.M., Zeng, X.Y., Koehl, L., Ventenat, V.: Textile, physiological, and sensorial parameters in sock comfort. Text. Res. J. 80(17), 1803-1810 (2010)

16. Bogerd, C.P., Niedermann, R., Brühwiler, P.A., Rossi, R.M.: The effect of two sock fabrics on perception and physiological parameters associated with blister incidence: a field study. Ann. Occup. Hyg. 56, 481-488 (2012)

17. Bruniaux, P., Crepin, D., Lun, B.: Modeling the mechanics of a medical compression stocking through its components behavior: part 1-modeling at the yarn scale. Text. Res. J. 82(18), 1833-1845 (2012)

18. Ke, W., Rotaru, G.-M., Hu, J.Y., Ding, X., Rossi, R.M., Derler, S.: Relationship between the friction and microscopic contact behavior of a medical compression stocking at different strains. Tribol. Lett. 56(3), 457-470 (2014)

19. Dowson, D.: Bio-tribology. Faraday Discuss. 156, 9-30 (2012)

20. Derler, S., Gerhardt, L.-C., Lenz, A., Bertaux, E., Hadad, M.: Friction of human skin against smooth and rough glass as a function of the contact pressure. Tribol. Int. 42(11-12), 1565-1574 (2009)

21. Rotaru, G.-M., Pille, D., Lehmeier, F.K., Stämpfli, R., ScheelSailer, A., Rossi, R.M., Derler, S.: Friction between human skin and medical textiles for decubitus prevention. Tribol. Int. 65 , 91-96 (2013)

22. Derler, S., Rao, A., Ballistreri, P., Huber, R., Scheel-Sailer, A., Rossi, R.M.: Medical textiles with low friction for decubitus prevention. Tribol. Int. 46(1), 208-214 (2012)

23. Heinrich, U., Koop, U., Leneveu-Duchemin, M.C., Osterrieder, K., Bielfeldt, S., Chkarnat, C., Degwert, J., Hantschel, D., Jaspers, S., Nissen, H.P., Rohr, M., Schneider, G., Tronnier, H.: Multicentre comparison of skin hydration in terms of physical-, physiological- and product-dependent parameters by the capacitive method (Corneometer CM 825). Int. J. Cosmet. Sci. 25(1-2), 45-53 (2003)

24. Stämpfli, R., Brühwiler, P.A., Rechsteiner, I., Meyer, V.R., Rossi, R.M.: X-ray tomographic investigation of water distribution in textiles under compression-possibilities for data presentation. Measurement 46(3), 1212-1219 (2013)

25. Derler, S., Rotaru, G.-M., Ke, W., El Issawi-Frischknecht, L., Kellenberger, P., Scheel-Sailer, A., Rossi, R.M.: Microscopic contact area and friction between medical textiles and skin. J. Mech. Behav. Biomed. Mater. 38, 114-125 (2014)

26. RAL Deutsches Institut für Gütesicherung und Kennzeichnung e.V., S.A.: Medical compression hosiery-quality assurance RAL-GZ 387/1 (2008) 